\title{
Álvares de Azevedo e Friedrich Schiller: possiveis diálogos entre a literatura e a filosofia do Romantismo
}

\begin{abstract}
Alexandre de Melo Andrade ${ }^{1}$
RESUMO: Alguns aspectos da poética de Álvares de Azevedo nos remetem à filosofia do pré-romântico alemão Friedrich Schiller. A alternância entre a natureza viva e a ausência dela, em Lira dos Vinte Anos, o jogo dos impulsos em Macário, e a concepção de "sublime", no prefácio de O Conde Lopo, dialogam, respectivamente, com a teoria da poesia sentimental, o conceito de liberdade e a definição de "sublime", expostos nos estudos de Schiller.

ABSTRACT: Some aspects from Álvares de Azevedo's poetry addresses to Freidrich Schiller's pre romantic philosophy. The alternation between live nature and its lack, in Lira dos Vinte Anos, the ambiguity of impulses in Macário, and the conception of "sublime", presented in the O Conde Lopo preface, dialogue respectively with the emotional poetry theory, the concept of freedom and the definition of "sublime", exposed in Schiller's studies.
\end{abstract}

PALAVRAS-CHAVE: Álvares de Azevedo, Friedrich Schiller, poesia, filosofia. KEYWORDS: Álvares de Azevedo, Friedrich Schiller, poetry, philosophy.

\section{Introdução}

As idéias disseminadas pelo primeiro grupo do Romantismo alemão encontraram eco em todos os romantismos. Embora a amplitude do movimento abarcasse idéias diversas, sendo mesmo impossivel dar a ele uma definição singular e genérica, há aspectos que se mantiveram num plano de similaridade, já que se interligam pela essência da alma romântica. Quando Anatol Rosenfeld e Jacó Ginzburg denominam o Classicismo como "o domínio diurno" da harmonia e do

\footnotetext{
1 Alexandre de Melo ANDRADE, Doutorando. Universidade Estadual Paulista "Júlio de Mesquita Filho" (UNESP-Araraquara). Título da pesquisa: A Natureza Transcendente em Álvares de Azevedo. E-mail: alexandremelo06@uol.com.br
} 
racionalismo (1993, p. 263), colocam em dúvida o olhar romântico, que se apraz com um grau elevado soturnidade. Essa passagem de valores absolutos para valores relativos acerca da vida incorpora as contradições da literatura romântica, especialmente exploradas pelos escritores que seguiram pela esfera do Mal-do-Século. A divisão, instaurada de forma intensa nesses escritores, está intimamente associada a pressupostos filosóficos das bases do Romantismo, quando no final do século XVIII já se produzia o gérmen da reflexão permanente sobre os valores que norteiam a trajetória humana.

Friedrich Schiller (1759 - 1805) colaborou para as idéias que se propagariam pelos romantismos, em especial no que se refere às contradições e ao choque entre a idealidade e o vazio. Suas considerações acerca dos impulsos humanos, instituídos sobre a ordem e a inclinação, a natureza e a legislação, o estado físico e o estado moral, intermediados pela possibilidade do jogo e da liberdade, direcionam nosso olhar aos conflitos instaurados pelos românticos.

Álvares de Azevedo (1831 - 1852), poeta romântico que traduziu de forma substancial os aspectos sombrios da literatura romântica européia, calcou seu lirismo sobre bases contraditórias que nos remetem à poesia sentimental aventada por Schiller. O poeta revela consciência dos pressupostos sobre os quais assentam seus versos, e joga com a possibilidade, a hesitação, a elevação e o rebaixamento. Macário, peça de extremo valor para o Romantismo brasileiro, atesta o jogo dos impulsos mencionados, que encaminham o ser ao desenvolvimento de sua liberdade, ou à sua própria perdição. Ao tentar definir o belo e o sublime, no prefácio de O Conde Lopo, mais uma vez nos deparamos, em certa medida, com a teoria schilleriana acerca do aspecto moral e da liberdade humana.

\section{I - A poesia sentimental}

Schiller, que pertenceu, ao lado de Goethe, à geração do Pré-Romantismo alemão, estabeleceu, com base na oposição 
Classicismo X Romantismo, um processo filosófico que aventa questões pertinentes sobre natureza, ruptura e reflexão. De acordo com o filósofo, a natureza corresponde à "subsistência das coisas por si mesmas, a existência segundo leis próprias e imutáveis" (1991a, p. 43); o homem, por outro lado, interfere em sua própria natureza. Mas nessa dissociação da natureza, ele se torna insatisfeito com a consciência que toma acerca de sua condição de errante e não sabe como voltar a ser natureza. Ser natureza novamente é a intenção do homem moderno; porém, nesta busca, ele se perde cada vez mais num labirinto atordoante, o que o separa ainda mais de seu primitivismo natural. Sobre isso, Rosenfeld diz que "os românticos de modo algum querem 'voltar' à natureza; querem avançar até ela, depois de assimilado todo o processo civilizatório" (1985, p. 154; aspas do autor).

Schiller chama de ingênuo o estado anterior à civilização, e sentimental o estado seguinte da perda da ingenuidade. Para ele, "o ingênuo na maneira de pensar jamais pode, por isso, ser uma qualidade de homens corrompidos, mas concerne apenas a crianças e homens de intenção infantil” (1991a, p. 49). O homem sentimental é como o adulto em relação à criança, sofre sua condição humana e deseja recuperar sua pureza. Os gregos, segundo Schiller, ignorando as dicotomias da consciência, representavam o próprio paraíso, o tempo anterior à especulação. A poesia moderna, para ele, é a dos que deixaram de ser natureza e são saudosos de recuperá-la. Como não há volta, percorrem o fio de uma existência dilacerada por pensamentos difusos; metamorfoseiam-se na figura de Satã, preenchem o vazio com certo obscurantismo e embriagam-se para suportarem a dor de existirem de forma fragmentada e nostálgica.

A rejeição ao mundo das formas concretas e das relações prosaicas instaurada pela literatura romântica empreendeu uma caminhada rumo às zonas inexploradas do ser, trazendo, dessa forma, o problema da subjetividade. Dessa desconfiança em relação à realidade, surgiram as narrativas fantásticas, o gosto pelo gótico, a ironia romântica e a poesia da dúvida. O choque entre o ser-natural e o 
ser-civilizado, resultante de uma consciência acerca dos desejos e dos limites, instituiu a desordem e o caos que sustentam a insatisfação do romântico em relação ao presente. Entre o infinito absoluto e o finito relativo situa-se o sujeito, visionário e contemplativo, desajustado e alheio, oscilando entre o seu impulso natural e a ordem estabelecida pelo senso comum.

A ironia romântica surge dessa consciência do caos instituído, da infinitude almejada e não alcançada, das contradições entre o rel presente e a idealidade vazia. Ronaldes de Melo e Souza afirma que a "ironia que se caracteriza como romântica, no sentido do Romantismo de Jena, postula o primado teórico da contradição e da inconclusividade do discurso genuinamente poético” (2004, p. 306) e, comentando os pressupostos de Schlegel, reitera que "a ironia poética constitui a forma de conhecimento em que a contradição é consentida" (idem).

Álvares de Azevedo incorporou, em seu programa poético, os pressupostos dessa dualidade referida por Schiller e por vários teóricos da ironia romântica. O poeta ofereceu-nos uma visão da poesia que transcende e rebaixa a condição humana ao dividir sua Lira dos Vinte Anos em duas partes fundamentais. A primeira parte apresenta poemas que elevam o sujeito-lírico a uma atmosfera carregada de perfumes e cores, onde as formas são vaporosas e a natureza encantadora; neste plano, Álvares de Azevedo transcende os elementos da natureza, elevando-os a uma condição espiritual. Por outro lado, a segunda parte da obra busca elementos prosaicos que projetam o desajuste do sujeito-lírico no mundo real, concreto e degradante; aqui, as marcas da civilização causam repulsa e o poeta zomba de um mundo que privilegia o dinheiro e o falso moralismo. Essa dualidade de abordagem temática foi referida pelo próprio poeta no prefácio da segunda parte da Lira dos Vinte Anos da seguinte forma: "É que a unidade deste livro funda-se numa binomia. Duas almas que moram nas cavernas de um cérebro pouco mais ou menos de poeta escreveram esse livro, verdadeira medalha de duas faces” (AZEVEDO, 2000, p. 190). 
Em “Um Cadáver de Poeta”, temos a figura de um trovador, morto na rua, exposto ao riso e ao desdém dos transeuntes, que o denominam "um pobre louco", um "insano / Amante de utopias e virtudes" e um pobre que "não valia a sepultura". Aqui, percebemos o enfrentamento entre a sensibilidade do poeta e a humanidade insensível e injusta à sua volta, desprovida de sonhos e entregue ao materialismo. Encontramos semelhante pressuposição, entre outros textos de Azevedo, na poesia "Minha Desgraça”, quando o poeta conclui:

\footnotetext{
Minha desgraça, ó cândida donzela, O que faz que o meu peito assim blasfema, É ter para escrever todo um poema E não ter um vintém para uma vela. (2000, p. 246)
}

São várias as formas como o poeta constata a desordem do mundo e muitas as demonstrações de tédio. No poema "Idéias Íntimas", reconhecido pela crítica como uma das melhores produções do poeta, encontramos um eu passeando pelo quarto, apreciando a imagem de poetas pertencentes ao cânone da literatura clássica e da literatura romântica, como Lamartine, Byron, Victor Hugo, Goethe, Dante, Shakespeare, entre outros. A todo momento há uma ênfase à desordem do quarto, microcosmo de um mundo às avessas, e ao "leito juvenil", onde diz dormir com os poetas. A fuga se estabelece, no poema, pela sonolência constatada através da constante referência ao quarto e à cama, e pela própria literatura, que tira o eu-lírico de sua realidade e provoca-lhe uma transcendência por meio do diálogo com a tradição poética. Seu tédio, aliado a uma monotonia angustiante e a um estado de melancolia, resulta da impossibilidade de ordenar o mundo conforme os ditames de sua sensibilidade.

Schiller, a par dessa transgressão, afirma que "o poeta sentimental sempre tem de lidar com duas representações e sensações conflitantes, com a realidade enquanto limite e com sua Idéia enquanto infinito, e o sentimento misto que desperta sempre testemunhará essa dupla fonte" (1991a, p. 64). Segundo Álvares de Azevedo, "O poeta 
acorda na terra", descobre-se situado entre o idealismo e a realidade, entre a adesão e a imanência.

\section{II - O jogo dos impulsos}

Nas Cartas de A Educação Estética do Homem, Schiller considera que há três instâncias que norteiam o progresso do homem em direção à sua própria natureza humana. A primeira corresponde à Natureza, ligada às inclinações pessoais, ao tempo anterior à crítica e à razão; trata-se do impulso sensivel, a vida em seu significado mais amplo. A segunda diz respeito ao oposto da primeira, ou seja, o Estado, regulador de atitudes, associado aos limites instituídos por uma maioria. A terceira resulta da conciliação entre as duas primeiras, de forma que o indivíduo não seja selvagem, obedecendo apenas aos seus impulsos, nem bárbaro, ocultando totalmente sua natureza intima em detrimento das leis mais universais. Nesta última fase situa-se a liberdade, o homem-humano, a estética.

Schiller reitera, aqui, o valor negativo da cultura, pois nela "experimentamos todas as infecções e todos os tormentos da sociedade, sem que daí surja um coração sociável” (1995, p. 36). A cultura não liberta, dessa forma, o homem; o entendimento separa o homem da natureza e faz dele uma engrenagem mecânica. O filósofo alemão atenta para a cisão que o desenvolvimento mecanicista provocou, afastando o homem da natureza e, por isso, de si mesmo.

Sobre o artista, Schiller afirma que é "do puro éter de sua natureza demoníaca que jorra toda a fonte da beleza, intocada pela corrupção das gerações e dos tempos” (1995, p. 54). Por essa razão, a verdade não estaria na realidade nem no tempo corrente, mas acima de qualquer convenção, o que faz da arte uma guardiã do que sobressalta ao senso comum e que toca a essência da própria liberdade humana.

Schiller propõe o balanceamento entre o impulso sensível (Natureza) e o impulso formal (Estado), do que resulta o impulso lúdico (necessidade física e moral a um só tempo). Podemos depreender daí 
que a falta de harmonia entre a natureza e o estado condiciona a reflexão, a inadaptação e a insatisfação. Sendo escravo da natureza ou legislador, o homem não se liberta, deixa de conhecer a liberdade. Os românticos sentem o choque entre a subjetividade, as inclinações, a natureza, e a objetividade, a civilização, a cultura; sentem-se tolhidos em relação à sua liberdade e, "descolados" da natureza, caminham em direção ao lúdico, ao gosto pessoal, embora não obtendo sucesso e fazendo desse ideal uma busca permanente.

Penseroso, Satã e Macário, personagens de Macário, de Álvares de Azevedo, relacionam-se, em certa medida, a essas três instâncias estabelecidas na teoria de Schiller. Satã é avesso às instituições, relativiza os costumes, desarma qualquer tensão em favor do arrastar-se pelos ditames de seus impulsos, pela noite e pelos aspectos demoníacos da vida. Em vários momentos, Macário, sujeito cindido pela existência corrupta, apresenta revolta e irritação, e obtém como resposta de Satã a bebida, o fumo, a abstinência de qualquer obediência aos apelos sociais. Penseroso, por outro lado, acredita no progresso, na civilização, na existência ordenada, e tenta reeducar Macário.

O personagem-título, desde o início, mostra-se arredio, febrilmente agitado, corroído pelo vício e pela desilusão; ele renega, até certo momento, a figura de Satã, mas também recusa as idéias de Penseroso, considerando-as apenas ilusões. Dessa forma, Macário encarna a própria cisão de que viemos falando, não conseguindo atingir a síntese entre a esperança e a civilidade de Penseroso (a "forma") e a natureza demoníaca de Satã (a "vida”). Ou seja, Macário não consegue atingir o que Schiller chama de "forma viva", o estado em que o ser joga entre seus desejos, suas inclinações, e as leis.

Unificando as qualidades que emergem do natural com aquelas do mundo artificial, "o homem conjuga a máxima plenitude e liberdade, abarcando o mundo em lugar de perder-se" (SCHILLER, 1995, p. 75). É quando ocorre a imposição da necessidade ao espírito física e moralmente, material e formalmente. O filósofo ainda considera 
que esse é o estado do belo, quando passividade e liberdade atuam na contingência, fazendo sobressair, no homem, sua própria humanidade.

O conceito de liberdade, para Schiller, está atrelado ao jogo que se estabelece entre a natureza íntima e a correspondência alheia; a sabedoria e a felicidade estariam, dessa forma, em conformidade com um considerável grau de consciência entre as duas realidades.

Através do fumo, do vinho, da orgia, Satã propõe a Macário o distensionamento da consciência, a fluidez dos desejos, a expansão de sua natureza. No primeiro diálogo que se estabelece entre eles, Satã, que ainda é apenas um Desconhecido, identifica em Macário traços de devassidão, lassidão e vício, e mostra-se companheiro, atencioso e desprovido de qualquer moralismo. Quando ambos se apresentam dizendo os nomes e apertando as mãos, ao fim deste primeiro diálogo, selam uma união que começa com a partida sobre um burro, já logo em seguida. Um tempo depois, Macário acorda na estalagem, aos gritos da mulher que lhe havia servido a ceia, e pensa ter sonhado a aventura com Satã, quando de repente percebe um trilho de pé no chão, que a mulher logo julga ter sido de algum diabo. Entre o sonho e a realidade, Macário caminha, marcado já pelo manifesto de suas forças sensíveis, rumo à sua degradação, acentuada pela presença atordoante de Penseroso.

A adesão de Macário aos desígnios de Satã, no final, e a morte de Penseroso após uma febre proveniente de suas lembranças e de seus desejos, insinuam que a sensibilidade se sobrepôs à retidão de conduta, e que o personagem em conflito resolveu existir poeticamente. A impossibilidade de acomodar os dois impulsos e viver em liberdade consciente fez com que um dos lados cedesse e instaurasse a anarquia, o arrastar-se pela noite adentro rumo a uma orgia, verdadeira escola do exercício de se ser naturalmente.

A dificuldade em conciliar os apelos da alma com os apelos sociais é um tópico desenvolvido de forma intensa pelos românticos. Daí emergem conflitos diversos, que normalmente levam os personagens à ruína moral e espiritual. O satanismo, representado pelos aspectos 
noturnos, pela ambiência lúgubre, pelos desejos frementes, pelo vício, e não raro pela própria figura de Satã, é característica marcante no Romantismo em geral, em especial no Mal-do-Século, e surge para dividir a consciência do sujeito entre interioridade e exterioridade, de forma que olhe para o mundo com desconfiança. Anatol Rosenfeld associa esse satanismo ao próprio niilismo, que se direciona a uma transcendência vazia, constatação de que não há fins que justifiquem os meios. Dilacerados, os românticos "se tornaram descobridores, andarilhos e peregrinos espirituais, conquistadores de mundos longínquos - mundo históricos, exóticos, folclóricos”, realçando ao mesmo tempo "o esfacelamento, o homem que vendeu a alma, o homem que vendeu a sombra e perdeu a estabilidade, a raiz [...]" (ROSENFELD, 1985, p. 161).

\section{III - O sublime}

O prefácio de O Conde Lopo, de Álvares de Azevedo, traz algumas passagens importantes para o nosso estudo. Ele discute o "belo" como sendo o fim de toda poesia e o poeta um missionário da beleza, não da beleza moral, mas daquela diretamente associada à imaginação. Para o poeta, há dois gêneros do belo: o doce e meigo, e o sublime. Para exemplificar o belo doce e meigo, considerado como o "belo mesmo", o poeta cita a águia no ninho "afagando as suas avezinhas, carregando-as nas antenas poderosas das asas, beijando-as, aquentando-as ao peito" (2000, p. 381). Para exemplificar o sublime, pede que o leitor imagine o céu nebuloso, os ventos esbravejando, toda a natureza em volta atacando esse ninho, e a águia lutando pelas suas crias, amparando-as até a morte. Nas duas manifestações do belo, o poeta faz alusão à natureza como fator preponderante: de um lado a natureza viva e harmônica do universo da águia; de outro lado, o universo em oposição, arrancando a águia e as crias dessa harmonia.

O sublime, nesse caso, assemelha-se à definição dada por Schiller. O filósofo entende o sublime como a resistência ao natural, o 
enfrentamento entre a passividade e a ação, pois isso não pode ser explicado mediante as leis da natureza, de causa e efeito. Por ser resistência, o sublime impõe ao homem dignidade, "descolamento" do mundo natural, sentido de humanidade. Schiller afirma, no ensaio Acerca do Sublime, que "nada há mais indigno do homem do que sofrer violência, pois a violência o nega. Quem a exerce sobre nós, não faz nada menos que contestar-nos a humanidade. Quem a suporta covardemente, despoja-se de sua humanidade" (1991b, p. 49). Como se vê, o sublime de Schiller está associado à resistência, que por sua vez, é o exercício pleno da liberdade.

Álvares de Azevedo classifica o sublime em três categorias: o sublime ideal, o sublime sentimental, e o sublime material. O poeta exemplifica o sublime ideal com imagens bíblicas de Jeová, de poetas da Judéia, de Deus do Sinai com voz trovejadora. Para mostrar o sublime sentimental, convida o leitor a ver a noite tenebrosa, a ventania rija nas montanhas, os clarões de incêndio do céu, um cadáver num madeiro e soluços angustiantes de mulheres aos pés da cruz. E o sublime material seria o estalar das florestas, a luta do vento com o mar, o mar querendo invadir nuvens e terras. Não é muito clara essa subdivisão que o poeta faz do sublime (já derivado de uma categoria do belo) em três aspectos.

Em "Agonia do Calvário", poema inserido no Canto I de $O$ Conde Lopo, o poeta parece querer explorar as categorias do sublime expostas no prefácio: ele abre o poema descrevendo uma tarde escura e fria, com vento rijo, um céu negro com azuis de relâmpagos cobrindo Jerusalém, e Cristo padecendo num madeiro.

E numa cruz pesada, áspera e dura, Um corpo frio e pálido!

Sangue negro em suor corre-lhe os membros, Prantos o rosto esquálido -

E os longos negros crespos - que a poeira

Das ruas polvilhara

D'espinhos, com irônico diadema

A turba coroara!

(2000, p. 408) 
Em seguida, o poeta traz para o cenário duas mulheres: Madalena, envolta num halo de pureza e impureza (o que é característico nas mulheres citadas pelo poeta), e Maria, choram olhando Cristo morto na cruz. Está claro que o poeta exemplifica o sublime sentimental referido no prefácio, quando já fazia referência à cena descrita. Essa imagem ganha força poética pela presença da natureza agitada ao redor, conforme observamos mais à frente:

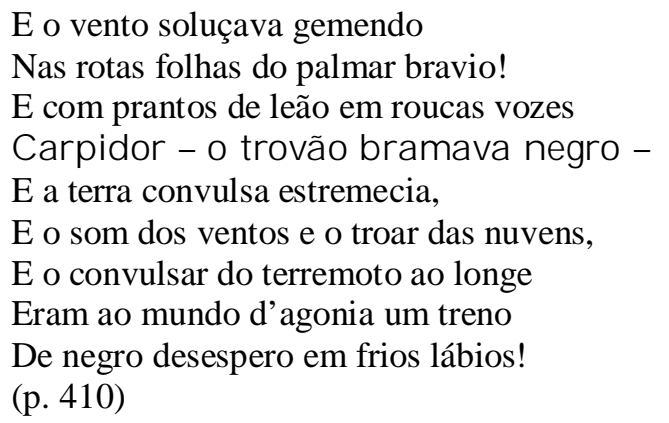

Todo esse aspecto revolto e negro da natureza corresponde àquele sublime material de que nos fala o poeta, que completa a cena de Cristo crucificado e o sofrimento das mulheres ao pé da cruz. Álvares de Azevedo parece querer ilustrar a própria teoria, disseminando ao longo do poema o sagrado e o sofrimento, a atividade da natureza e a possibilidade de resistência apresentada pelos personagens. O que resulta disso é um poema considerado pela crítica como imaturo, repleto de clichês românticos, que não revela o verdadeiro talento poético de Álvares de Azevedo.

Segundo Antonio Candido, nos poemas de Azevedo,

As imagens evanescentes despertam o sentimento do belo ideal; as imagens que enternecem correspondem ao belo sentimental; as que ferem vivamente os sentidos, ao belo material. O sublime ideal decorre das imagens que exaltam e transportam; o sublime sentimental, das que comovem e desesperam; o sublime material, das que atemorizam e despertam a admiração. (2000, p. 319)

Schiller associa o sublime à idéia de resistência. Para ele, o estado do nosso espírito não necessariamente deve ser conduzido 
mediante as mesmas leis da natureza, e que trazemos um princípio autônomo que independe das emoções sensíveis. Nesse sentido, a resistência que caracteriza o sublime é a prática da liberdade, é o uso da própria consciência para impor-se dignidade. Entendemos, então, que o sublime se manifesta, nas personagens acima de O Conde Lopo, através do próprio silêncio mediante uma condenação que chega às vias de fato e que culmina com a morte do Cristo, pois o silêncio como escolha impõe dignidade através da demonstração da contenção emocional. Madalena e Maria já estão, por si mesmas, comovidas pelo aspecto sublime da morte de Cristo, que usa de uma liberdade consciente para entregar-se à morte.

Para Schiller, "A capacidade de sentir o sublime é, pois, uma das mais esplêndidas faculdades humanas [...]" (1991b, p. 68), é o que faz do homem um ser moral, "humano", e conseqüentemente estético. O filósofo alemão ainda considera que apenas a resistência ao sofrimento é patética e digna de representação, pois apresenta oposição ao limite da natureza. Por essa mesma razão, Álvares de Azevedo considera que o sublime é um belo ainda mais alto: comove-nos pelo enfrentamento entre o contexto deprimente e as forças plenas do homem.

\section{Referências Bibliográficas}

ÁlVARES DE AZEVEDO, M. A. Lira dos Vinte Anos. In: Org. Alexei Bueno. Rio de Janeiro: Nova Aguilar, 2000. Obra Completa. . O Conde Lopo. In: . Obra Completa. Org. Alexei Bueno. Rio de Janeiro: Nova Aguillar, 2000.

. Macário. In: Obra Completa. Org. Alexei Bueno. Rio de Janeiro: Nova Aguillar, 2000.

CANDIDO, A. A Crítica Viva. In: Formação da Literatura Brasileira (Momentos Decisivos). $6^{\text {a }}$ ed. Belo Horizonte: Editora Itatiaia Ltda, 2000. (p. 317 a 325)

GINZBURG, J; ROSENFELD, A. Romantismo e Classicismo. In: GUINSBURG, J. O Romantismo. São Paulo: Perspectiva, 1993.

MELO E SOUZA, R. de. Poesia e filosofia no Romantismo. In: JUNQUEIRA, I. (coord.) Escolas Literárias no Brasil. Rio de Janeiro: ABL, 2004. (p. 301 341)

ROSENFELD, Anatol. Aspectos do Romantismo alemão. In: Contexto. $4^{\text {a }}$ ed. São Paulo: Perspectiva, 1985. - Texto / 
SCHILLER, Friedrich. A Educação Estética do Homem. Trad. Roberto Schwarz e Márcio Suzuki. São Paulo: Iluminuras, 1995.

- Poesia ingênua e sentimental. Trad. Márcio Suzuki. São Paulo: Iluminuras, 1991a.

. Acerca do Sublime. In: Teoria da Tragédia. Trad. Flavio Meurer. São Paulo: EPU, 1991b. 